\title{
Effects of Curvature and Area Distribution on S-Shaped Subsonic Diffuser Performance
}

\author{
Harun GÖKÇE*, Umut Can KÜÇÜK**, İsmail ŞAHİ**** \\ *TÜBITTAK Defense Industries Research and Development Institute, 06261 Ankara, Turkey, \\ E-mail: harungokce@yahoo.ca \\ **TÜBITTAK Defense Industries Research and Development Institute, 06261 Ankara, Turkey, \\ E-mail: kucukumutcan@gmail.com \\ ***Gazi University, Technology Faculty, Industrial Design Engineering Department, 06500 Ankara, Turkey, \\ E-mail: isahin@gazi.edu.tr
}

crossref http://dx.doi.org/10.5755/j01.mech.24.6.22460

\section{Introduction}

The aim of the engine intake is providing air to the aircraft engine components with an adequate reduction in flow velocity, minimum total pressure loss and maximum flow uniformity [1]. Low radar cross section and high packaging efficiency requirements lead intake designers to use high offset short diffuser designs. However, these kinds of intakes are very prone to flow separation due to a high diffusion rate through the duct and sharp streamline curvature. Therefore, developing a design methodology and understanding the effects of geometrical properties on intake performance is crucial for proper intake design. Centerline curvature and area ratio is one of the two main factors that effecting intake performance. Total pressure distortions at the aerodynamic interface plane and pressure recovery are the two important performance descriptor of an intake. Total pressure distortion which is the indicator of the flow-non uniformity reaching Aerodynamic Interface Plane (AIP) is one of the most important parameters affecting intake/engine compatibility [2].

At the end of 1950's, with the development of the computer technologies computational studies have become widespread, and commercial Computational Fluid Dynamics (CFD) tools have been started to use to solve fluid dynamics problems [3]. Expensive and exhaustive experimental works give way to cost-friendly CFD analysis among the designers. Recently, CFD is the most popular tools in the intake design and analyses. Many researchers have used CFD tools to determine aerodynamic performance in lately [4-11]. Computer-based optimization techniques were developed as a result of these numerical analyzes that were successful. In computer-aided design optimization studies over the intake geometry in literature, distortion coefficient and pressure recovery parameters are commonly used.

Zhang et. al. investigated of S-Shaped intake design using multi-objective and multi-disciplinary techniques. They integrated the existed mathematical optimization methods on CFD results which are included S-Shaped intake design parameters [12]. Reddy similarly used automated design synthesis that is interfaced with CFD solver and grid generation code for a finding of optimum subsonic S-Shaped intake design. He changed lip shape by using parametric modeling techniques [13]. Lee at al. was investigated the effects of design parameters of 3D intake performance by using commercial CFD code. They handled the pressure recovery at the intake exit plane though numerical analyses of $3 \mathrm{D}$ turbulent flow by changing ramp angle, the width of throat and effects of mass flow rate and angle of attack [14]. Wellborn and Okiishi created aerodynamic data for compressible S-Shaped intake model. The generated model was validated with experimental tests and numerical solutions. This methodology was used to understand the flow phenomenal of S-Shaped intake geometry [15].

Berrier et al. conducted an experimental research of a flush-mounted, S-Shaped intake that ingesting large amounts of the boundary layer. In addition to the experimental study, they managed computational studies of this intake by using Navier-Stokes solver OverFlow to direct their aim to present a database for CFD tool validation on this type of intake and provide a baseline intake for future intake flow control studies [16]. Allan and Owens conducted validation of NASA developed RANS flow solver OverFlow for a boundary layer ingesting intake in high subsonic flow regime with passive and active flow control devices [17]. Sun, Guo and $\mathrm{Wu}$ worked to enhance submerged intake performance with flush mounted planar side entrance. They determined three significant parameters side edge angle, ramp angle and parameter of aft lip and they studied the effects of these parameters on the intake performance by both experiment and computational fluid dynamic [18].

Rabe conducted an experimental and numerical investigation in a static ground test facility to determine the flow quality of an intake shape integrated with flow control for simulated flight conditions [19]. Nichols and Pierpont conducted an experimental investigation of boundary layer suction slots placed upstream submerged intakes. They examined the effect of the boundary layer suction slots quantity and placement, on the intake performance [20]. Pierpont and Howell also handled the experimental investigation of boundary layer suction slots for semi-submerged air scoop at low speeds. As their study boundary layer suction slots increase the pressure recovery of the intake, but the position of the suction slot is not found as critical. Area of the suction is effective for the intake performance according to their work. It can be stated that from the past investigations and works about performance improvements, different methods are held and become a successful enhancement of performance [21].

Different from the literature in this study, effects of curvature and area distribution on S-Shaped subsonic diffuser performance were computationally investigated using 
CFD (Fig. 1). Free-stream Mach number was taken as 0.75 for all computational runs while sideslip and angle of attack values vary between 0 and 5 . Intake performance criterions; DC and PR are depicted from the computational domain and dependence of these parameters to the varying centerline curvature and area ratio for each flight condition is discussed.

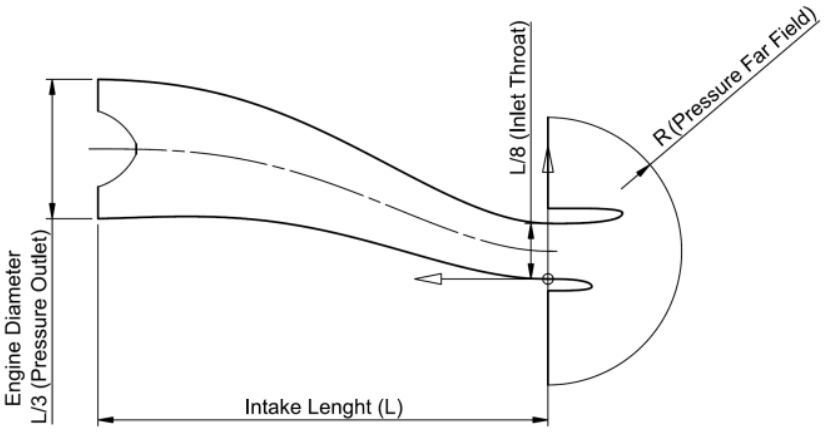

Fig. 1 Intake geometry definition and CFD boundary conditions

\section{Method}

Inlet distortion can result install in compressor blades or even surge. Compressor surge usually combined with a high level of structural vibrations and noise which often cause some severe structural damage on the compressor blades. Although it is possible to find many distortion coefficients in the literature, DC (60) used in this work as a distortion coefficient. Total pressure distortion occurred at the engine face is calculated with the following formula [1]:

$$
D C(\theta)=\frac{\left(P_{f}-P_{\theta}\right)}{q_{f}} .
$$

In this equation, $P_{f}$ and $q_{f}$ indicating the mean total pressure and the mean dynamic pressure at the engine face respectively whereas $P_{\theta}$ is the mean total pressure of the lowest value obtained at the engine face in a certain circumferential extent limited by the angle $\theta$. The $\theta$ must be selected carefully in order to represent intake/engine compatibility satisfactorily to build adequate engineering procedure. At the same time, pressure recovery measure ability of an air intake to converting free stream energy into the usable energy for the engine components. Reduction in pressure recovery may lead to a reduction in available thrust and range. Total pressure recovery (PR) is calculated as following [2]:

$$
P R=\frac{P_{f}}{P_{t \infty}} .
$$

In the above equation, $P_{f}$ and $P_{t \infty}$ represent total pressure values at the engine face and free stream respectively.

2.1. General characteristics of investigated centerline curvatures and area ratios

In the present study performance of nine different intake geometry formed by the coupling of three different area ratios and three different centerline curvatures is investigated. Properties of intake entrance and engine face are held constant for all geometries. Investigated intake duct has an area ratio of 1.7 with non-dimensionalized centerline offset equal to 0.26 with respect to intake length. Investigated centerline curvatures have three different characteristics, one has a sharp turn at the first bend of intake and other has low curvature at the entrance. The last centerline curvature has equal turn angles at first and second bends of the intake. Centerline curvatures used in this study are shown in the Fig. 2.

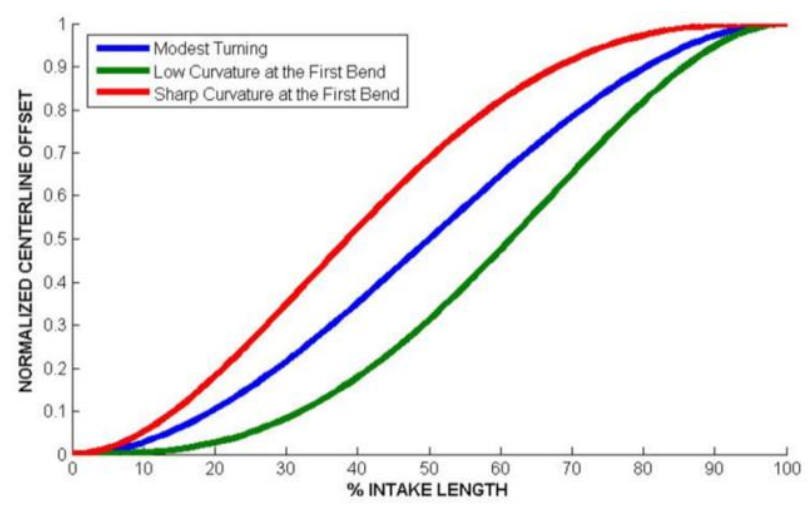

Fig. 2 Investigated centerline curvatures

Simultaneously, three different area ratios with three different characteristics are modeled in order to observe the effects of area ratio and centerline curvature in a coupled manner. One of the area ratios dictates a high diffusion rate around the intake throat while the other around engine face. Third area ratio dictates equally distributed diffusion through the duct. These area variations along intake length are shown in the Fig. 3.

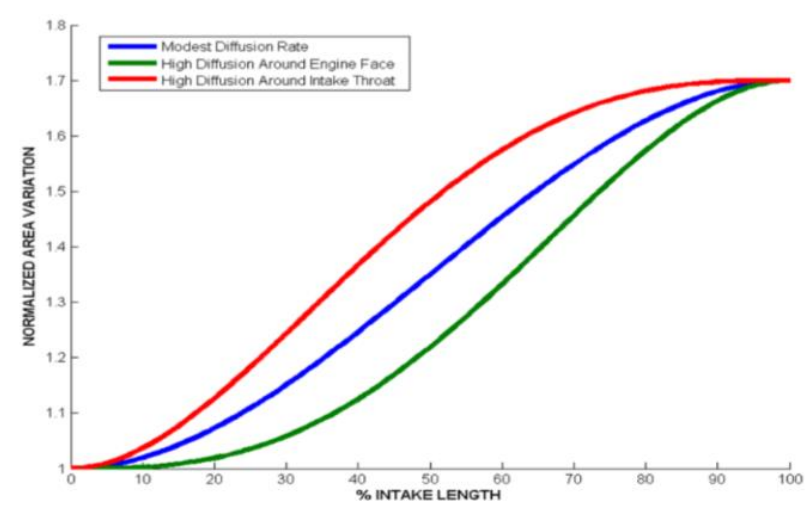

Fig. 3 Investigated diffusion rates

Simultaneously, three different area ratios with three different characteristics are modeled in order to observe the effects of area ratio and centerline curvature in order to separate each geometry formed by coupling different diffusion and centerline characteristics, a naming methodology was used such that A1, A2, and A3 indicate area distributions with high diffusion rate around intake throat, high diffusion rate around engine face and modest area distribution respectively. Similarly, C1, C2, and C3 indicate centerline curvatures with a sharp turn at the first bend, smoothest turn around the first bend and modest turn through intake respectively. Therefore geometry named $\mathrm{A} 1 \mathrm{C} 1$ has characteristics such that both high diffusion rate and sharp curvature is at first bend of the intake. General characteristics and naming of the investigated intake geometries are summarized in Table 1. 
Design methodology for investigated intake ducts

\begin{tabular}{|c|l|l|}
\hline Geometry Name & \multicolumn{1}{|c|}{ Characteristic of Centerline Curvature } & \multicolumn{1}{c|}{ Characteristic of Area Distribution } \\
\hline A1C1 & Low Curvature at the First Bend & High Diffusion Rate Around Intake Throat \\
\hline A2C1 & Low Curvature at the First Bend & High Diffusion Rate Around Engine Face \\
\hline A3C1 & Low Curvature at the First Bend & Modest Diffusion Rate Through Intake \\
\hline A1C2 & High Curvature at the First Bend & High Diffusion Rate Around Intake Throat \\
\hline A2C2 & High Curvature at the First Bend & High Diffusion Rate Around Engine Face \\
\hline A3C2 & High Curvature at the First Bend & Modest Diffusion Rate Through Intake \\
\hline A1C3 & Modest Curvature & High Diffusion Rate Around Intake Throat \\
\hline A2C3 & Modest Curvature & High Diffusion Rate Around Engine Face \\
\hline A3C3 & Modest Curvature & Modest Diffusion Rate Through Intake \\
\hline
\end{tabular}

\subsection{Computational analysis}

CFD simulations all external boundaries excluding symmetry plane are defined as pressure far field whereas pressure outlet boundary condition is given to the engine face. The other parts of the modeled geometry are defined as a wall with the no-slip condition. Fixed static pressure value determined from engine mass flow demand is applied to the engine face boundary condition with a total temperature equal the free stream value. In order to capture near wall region flow, 20 layers of boundary layer elements are created with a $\mathrm{Y}+$ value near 1 . Calculations collected by using pressure based coupled solver with least square cell-based method. For all calculations, the 2nd order upwind scheme with $k \omega S S T$ turbulence model is applied. Investigated flow domain is shown in the Fig. 4.

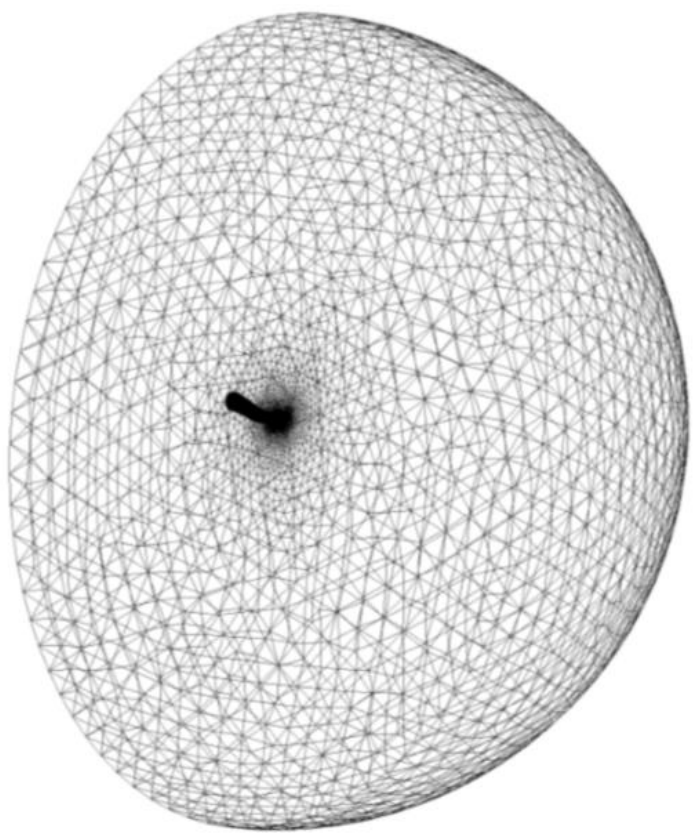

Fig. 4 Computational domain of the CFD models

\section{Results and discussion}

The main purpose of this study is to investigate the effect of centerline curvature and area ratio on the PR and DC values. Additionally, investigating static pressure distribution at the symmetry plane of intake can give valuable insight to the reader about how flow characteristics inside the inlet affected by area ratio and centerline curvature. The figures and graphs showing the static pressure distributions were normalized according to the maximum static pressure at the air inlet. Values range from 0.40 to 1 .
Normalized static pressure distribution at the symmetry plane obtained with each geometry is given in the Fig. 5 only for a single flow condition in which angle of attack and side slip angle is zero. In this figure, it can be seen that for a constant centerline curvature, changing area ratio has a direct effect on static pressure distribution and it is possible to size low and high-pressure regions inside the inlet. Similarly, for a constant area ratio changing characteristics of centerline curvature effects magnitude of the lowpressure region occurred around inlet throat. Characteristic of centerline curvature also affects the shape of low and high-pressure regions.

Investigation of symmetry plane static pressure distributions gives a general insight into how flow characteristics inside the inlet are changing with centerline curvature and area ratio. However, as already mentioned inlet performance is generally characterized by total pressure distortion and pressure recovery. Therefore, these performance criterions are obtained with each inlet geometry from CFD analyses. Additionally, in order to understand the performance of each inlet geometry at different angles of attack, computations are carried out at 0deg and 5deg angle of attack values with keeping side slip angle as 0deg. Similarly, to investigate the effect of sideslip angle additional computations are conducted at $0 \mathrm{deg}$ and $5 \mathrm{deg}$ side slip angles by keeping the angle of attack as 0deg. Total pressure distribution at engine face obtained with each inlet geometry at each flow condition is given in the Fig. 9 and Fig. 10. DC (60) and PR values obtained with each inlet at 0 -degree angle of attack and side slip angle is summarized in Fig. 6. This figure clearly indicates that lowest distortion at this flow conditions is obtained with centerline which has strong curvature at the first bend and distortion values increases as the strong curvature gets closer to the engine face. Furthermore, the effect of area variation on distortion is changing with centerline curvature characteristics and it has a relatively small effect. At the same time, it can be also seen that changing the area ratio and centerline curvature has an only limited effect on total pressure recovery. Therefore, it is not applicable to make clear conclusions related to the effect of investigated design variables on total pressure recovery at this flow condition.

Understanding effect of sideslip angle on inlet performance can also be important for designing an engine inlet for the special air vehicle. Therefore, DC (60) and PR values obtained with each inlet geometry at a 0 -degree angle of attack and 5-degree side slip angle is given in the Fig. 8. As can be depicted from this figure, increase in sideslip angle leads to a significant increase in DC (60). At the same time, high levels of PR values can still be obtained with investi- 
gated inlet geometries. At this flow condition, lowest distortion values are obtained with centerline curvature which has equal turn angles at first and second end of the inlet. But centerline with strong curvature at first bend gives comparable distortion values with the modest centerline curvature.
At this flow condition, it can also be concluded that inlet geometries with high diffusion rate closer to the engine face have relatively high performance in terms of both PR and DC (60). But the effect of area distribution is still less significant compared to the effect of centerline curvature.

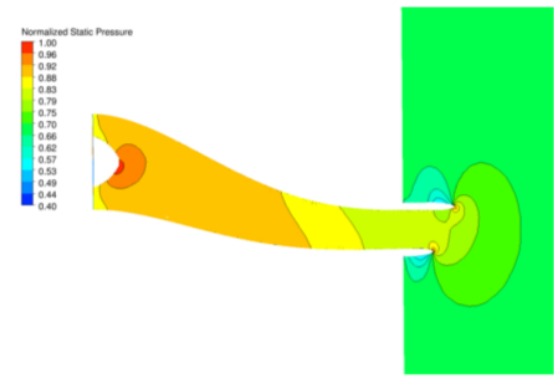

a) $\mathrm{A} 1 \mathrm{C} 1$

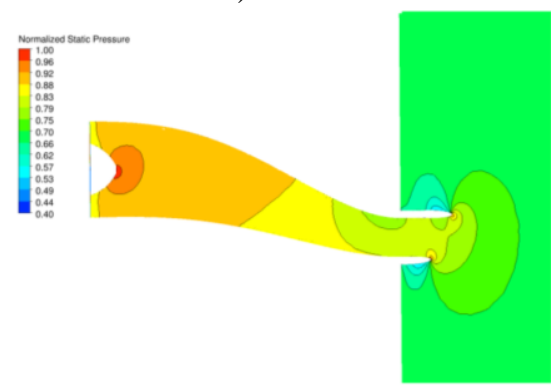

d) $\mathrm{A} 1 \mathrm{C} 2$

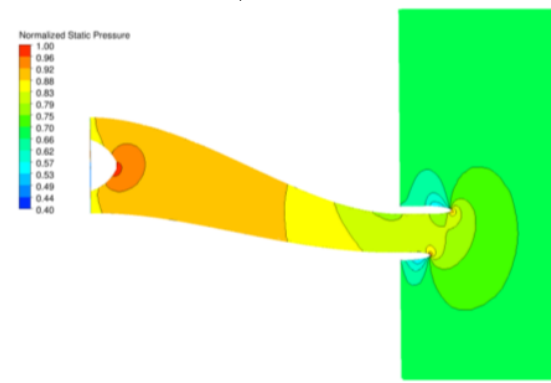

g) $\mathrm{A} 1 \mathrm{C} 3$

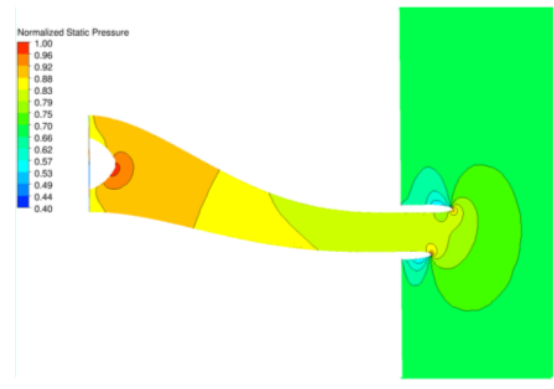

b) $\mathrm{A} 2 \mathrm{C} 1$

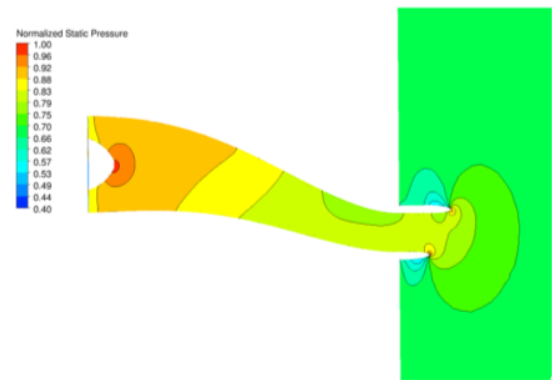

e) $\mathrm{A} 2 \mathrm{C} 2$

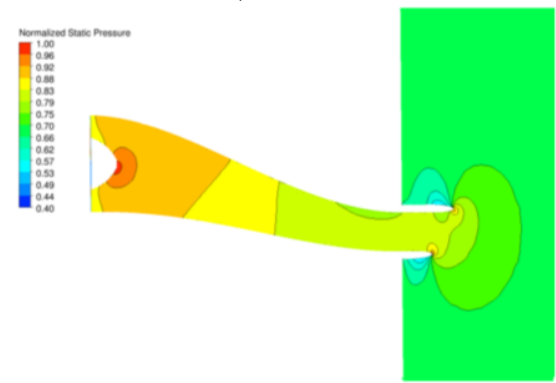

h) $\mathrm{A} 2 \mathrm{C} 3$

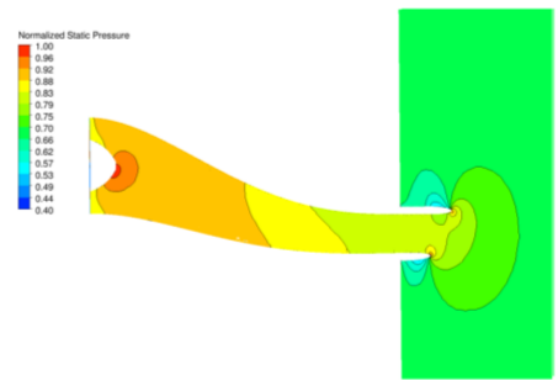

c) $\mathrm{A} 3 \mathrm{C} 1$

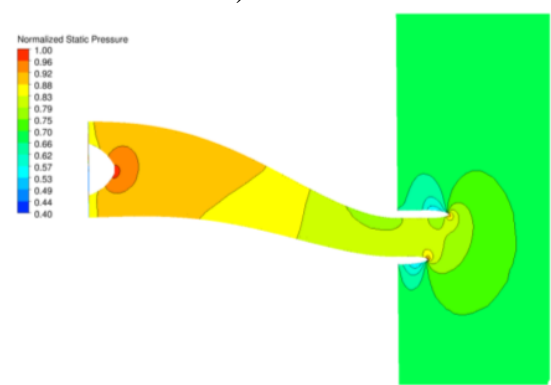

f) $\mathrm{A} 3 \mathrm{C} 2$

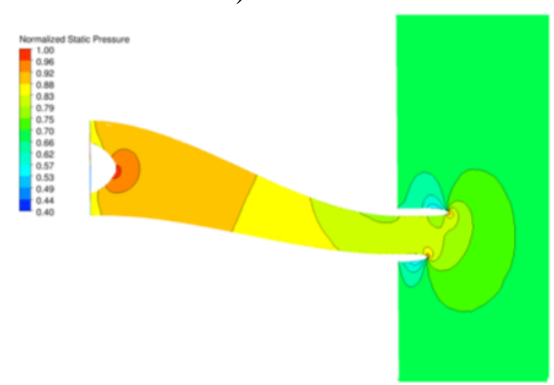

i) $\mathrm{A} 3 \mathrm{C} 3$

Fig. 5 Static pressure distribution at symmetry plane at Odeg AOA (Angle of Attack) and Odeg BETA (Side slip angle)

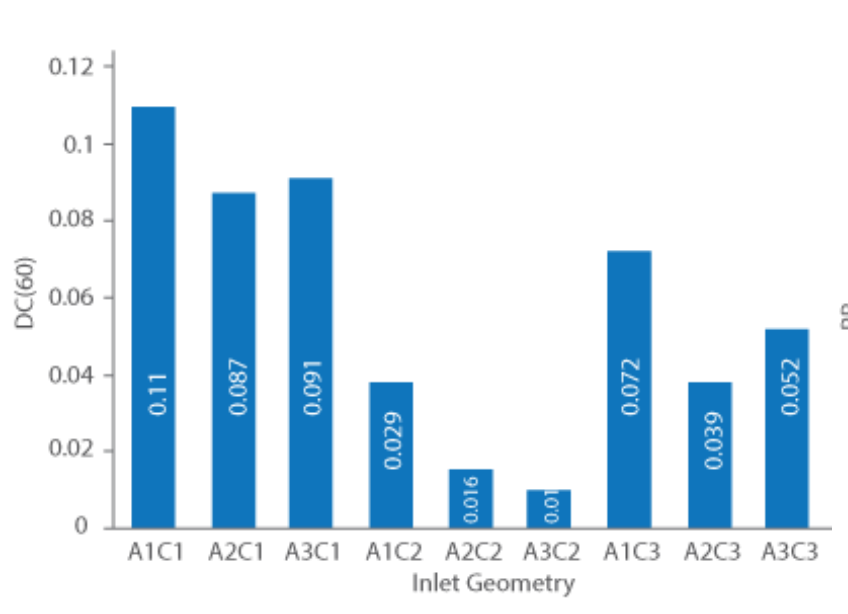

a) DC (60)

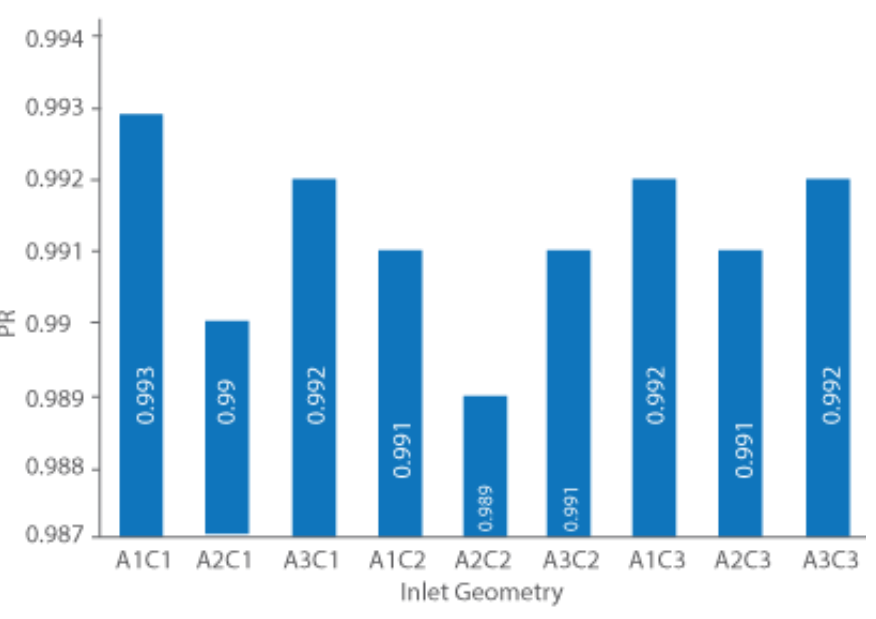

b) PR

Fig. 6 Static pressure distribution at symmetry plane at Odeg AOA and Odeg BETA

Performance of each geometry at a 5-degree angle of attack and 0-degree side slip angle is also obtained to investigate inlet performances with increasing angle of attack. Results of these investigations are summarized in Fig. 7.
From this figure, it is seen that with an increase in angle of attack general decrease in total pressure distortion and a general increase in pressure recovery is obtained. However, minimum obtained DC (60) is increased. Similar to an 


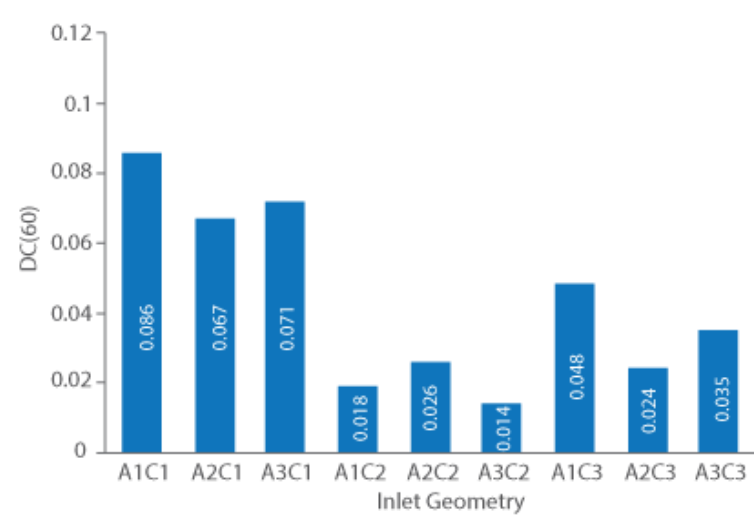

a) DC (60)

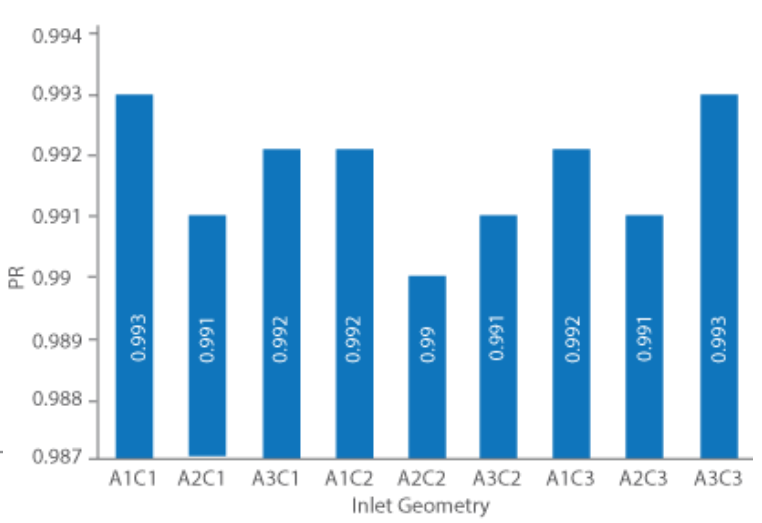

b) PR

Fig. 7 Static pressure distribution at symmetry plane at 5deg AOA and 0deg BETA

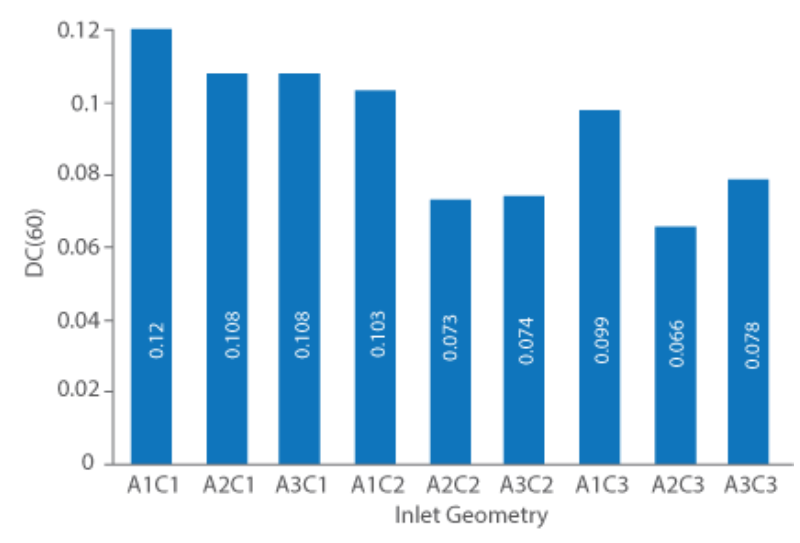

a) DC (60)

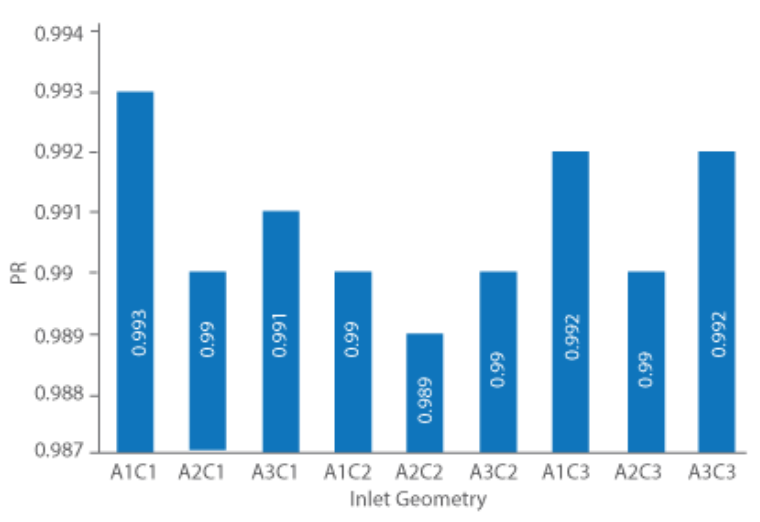

b) PR

Fig. 8 Static pressure distribution at symmetry plane at 5deg AOA and 0deg BETA

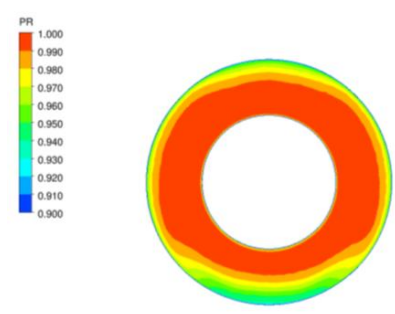

a) $\mathrm{A} 1 \mathrm{C} 1$

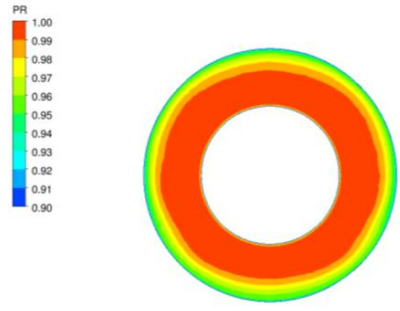

d) $\mathrm{A} 1 \mathrm{C} 2$

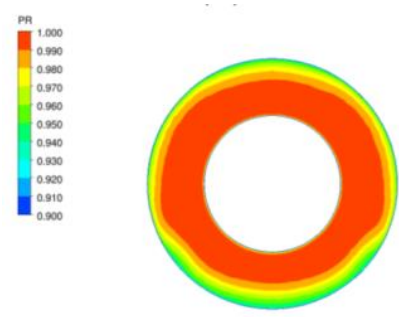

g) $\mathrm{A} 1 \mathrm{C} 3$

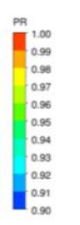

b) $\mathrm{A} 2 \mathrm{C} 1$
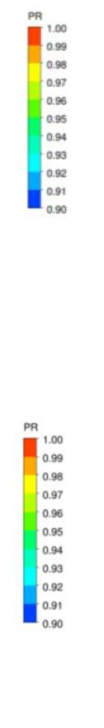

h) $\mathrm{A} 2 \mathrm{C} 3$

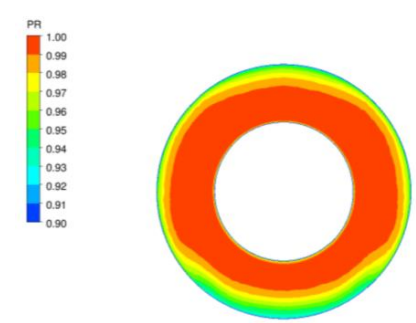

c) $\mathrm{A} 3 \mathrm{C} 1$
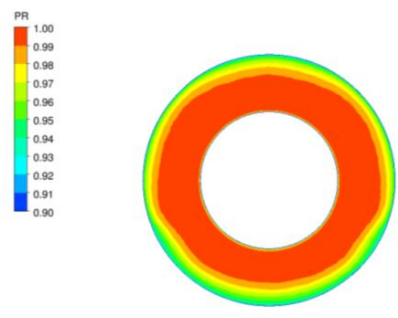

f) $\mathrm{A} 3 \mathrm{C} 2$
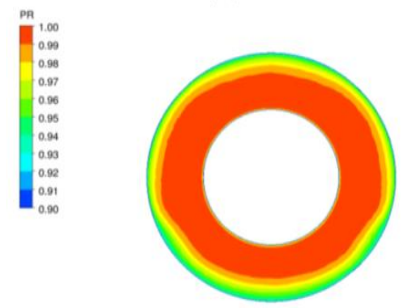

1) $\mathrm{A} 3 \mathrm{C} 3$

Fig. 9 PR contours obtained with different geometries at 5deg AOA and 0deg BETA (Eq. (2)) 


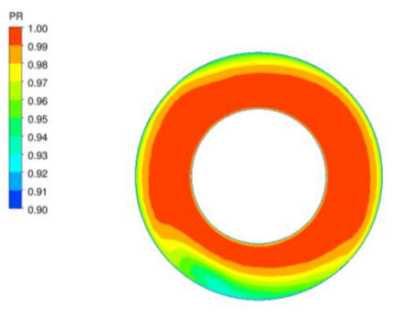

a) $\mathrm{A} 1 \mathrm{C} 1$

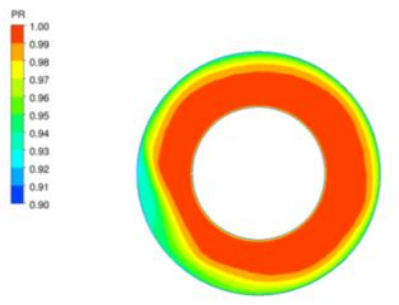

d) $\mathrm{A} 1 \mathrm{C} 2$

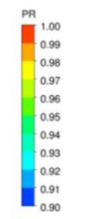

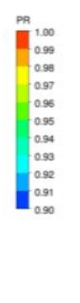

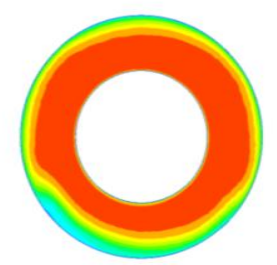

b) $\mathrm{A} 2 \mathrm{C} 1$
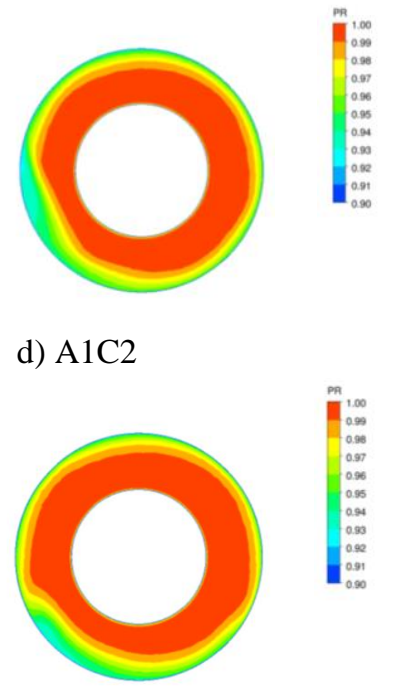

g) $\mathrm{A} 1 \mathrm{C} 3$

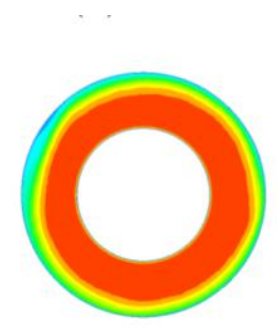

e) $\mathrm{A} 2 \mathrm{C} 2$

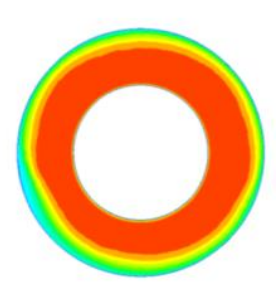

h) $\mathrm{A} 2 \mathrm{C} 3$

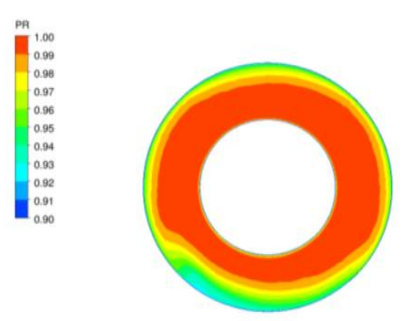

c) $\mathrm{A} 3 \mathrm{C} 1$
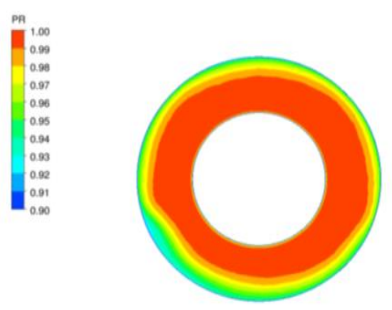

f) $\mathrm{A} 3 \mathrm{C} 2$
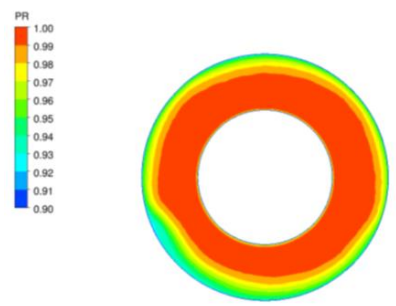

1) $\mathrm{A} 3 \mathrm{C} 3$

Fig. 10 PR contours obtained with different geometries at 0deg AOA and 5deg BETA (Eq. (2))

earlier investigation conducted for the 0-degree angle of attack, using centerline which has strong curvature at the first bend results in lowest distortion and moving strong curvature to the engine face results in general increase in distortion. Furthermore, the effect of area ratio on distortion depends on centerline curvature characteristics. Effect of area ratio and centerline curvature is still in limited extent for this flow condition.

Understanding effect of sideslip angle on inlet performance can also be important for designing an engine inlet for the special air vehicle. Therefore, DC (60) and PR values obtained with each inlet geometry at a 0 -degree angle of attack and 5-degree side slip angle is given in the Fig. 8. As can be depicted from this figure, increase in sideslip angle leads to a significant increase in DC (60). At the same time, high levels of PR values can still be obtained with investigated inlet geometries. At this flow condition, lowest distortion values are obtained with centerline curvature which has equal turn angles at first and second end of the inlet. But centerline with strong curvature at first bend gives comparable distortion values with the modest centerline curvature. At this flow condition, it can also be concluded that inlet geometries with high diffusion rate closer to the engine face have relatively high performance in terms of both PR and DC (60). But the effect of area distribution is still less significant compared to the effect of centerline curvature.

\section{Conclusions}

In this study, the effects of characteristics of centerline curvature and area ratio on the inlet performance at 0 and 5 degrees of angle of attack and sideslip angles are computationally investigated. Results indicate that centerline curvature has a primary effect on distortion whereas the effect of investigated area ratios on distortion is only in limited extent and it generally depends on the characteristics of centerline curvature (Fig. 9). At the same time, the effect of design variables on pressure recovery is not significant for the investigated flow conditions. Probably more clear conclusions can be done about the effect of design variables on pressure recovery; if negative effects originate from intake/airframe integrations like boundary layer ingestion is taken into account (Fig. 10).

According to the results of this study, low distortion and high PR values can be obtained with centerline curvature which has sharp curvature at the first bend and with smooth area increase through the inlet. Furthermore, it can also be concluded that at a small angle of attacks higher inlet performance can be obtained whereas increasing side slip angle has significant negative effects on inlet performance.

\section{References}

1. Küçük, U. C.; Özgür, U. B.; Oguz, U. 2015. Passive flow control in boundary layer ingesting semisubmerged inlet, 51st AIAA/SAE/ASEE Joint Propulsion Conference: 1-8., Orlando, USA. https://doi.org/10.2514/6.2015-3803.

2. Seddon, J. M.; Goldsmith, E. L. 1999. Intake aerodynamics, AIAA Education Series, Blackwell Science, United Kingdom. 
3. Akman, O. 2014. Subsonic transonic submerged intake design for a cruise missile, Master Thesis, Middle East Technical University, Ankara, Turkey.

4. Sacks, A. H.; Spreiter, R. J. 1951. Theoretical investigation of submerged inlets at low speeds, National Advisory Committee for Aeronautics, UNT Libraries Government Documents Department, USA.

5. Rolls, L. S. 1953. A flight comparison of a submerged inlet and a scoop inlet at transonic speeds, [online] [accessed 19 May. 2018]. Available from Internet: http://www.dtic.mil/dtic/tr/fulltext/u2/005157.pdf.

6. Albers, J. A.; Miller, B. A. 1973. Effect of subsonic inlet lip geometry on predicted surface and flow mach number distributions, National Aeronautics and Space Administration, [online] [accessed 19 May. 2018]. Available from Internet:

https://archive.org/details/nasa_techdoc_1974000369.

7. Laruelle, G. 2002. Air intakes: role, constraints and design, International Council of the Aeronautical Sciences Congress: 643.1-643.16., Toronto, Canada.

8. Nasuhubey, B. 2014. Vortex generator design for high subsonic inlets, Master Thesis, Middle East Technical University, Ankara, Turkey.

9. Anabtawi, A. J.; Blackwelder, R. F.; Lissaman, P. B. S.; Liebeck, R. H. 1999. An experimental investigation of boundary layer ingestion in a diffusing S-Duct with and without passive flow control, 37th Aerospace Sciences Meeting and Exhibit, Aerospace Sciences Meetings, Reno, NV, USA. https://doi.org/10.2514/6.1999-739.

10. Hamstra, J.; Miller, D.; Truax, P.; Anderson B.; Wendt, B. 2000. Active inlet flow control tTechnology demonstration, 22nd International Congress of Aeronautical Sciences: 6112.1-6112.10, Harrogate International Conference Centre, UK.

11. He, H.; Li, X. 2011. Design of S-shaped submerged inlet, Advanced Materials Research 291-294: 349-354. https://doi.org/10.4028/www.scientific.net/AMR.291294.349.

12. Zhang, J.; Wang, C.; Lum, K. 2008. Multidisciplinary design of S-shaped intake, 26th AIAA Applied Aerodynamics Conference, AIAA 2008-7060, Honolulu, Hawaii. https://doi.org/10.2514/6.2008-7060.

13. Reddy, D. R.; Reddy, E. S.; Moody, R. E. 1998. Aerodynamic shape optimization of a subsonic inlet using 3D Euler computation, Journal of Propulsion and Power 14(2): 225-233.

14. Lee, J. G.; Jung, S. Y.; Ahn, C. S. 2004. Numerical simulation of 3D flows for flush inlet, 22nd Applied Aerodynamics Conference and Exhibit, Providence, Rhode Island. https://doi.org/10.2514/6.2004-5190.

15. Wellborn, S. R.; Okiishi, T. H.; Reichert, B. A. 1993. A study of the compressible flow through a diffusing Sduct, NASA Lewis Research Center, 1993.

16. Berrier, B. L.; Carter, M. B.; Allan, B. G. 2005. High Reynolds number investigation of a flush-mounted, Sduct inlet with large amounts of boundary layer ingestion, National Aeronautics and Space Administration, NASA/TP-2005-213766.
17. Allan, B.; Owens, L. R. 2006. Numerical modeling of flow control in a boundary-layer-ingesting offset inlet diffuser at transonic mach numbers, 44th AIAA Aerospace Sciences Meeting and Exhibit, Reno, Nevada. https://doi.org/10.2514/6.2006-845.

18. Sun, S.; Guo, R.; Wu, Y. 2007. Characterization and performance enhancement of submerged inlet with flush mounted planar side entrance, Journal of Propulsion and Power 23(5): 987-995, https://doi.org/10.2514/1.26432.

19. Rabe, A. C. 2003. The effectiveness of a serpentine inlet duct flow control scheme at design and off-design simulated flight conditions, Ph.D. Thesis, Virginia Polytechnic Institute, and State University.

20. Nichols, M. R.; Pierpont, P. K. 1950. Preliminary investigation of a submerged air scoop utilizing boundarylayer suction to obtain increased pressure recovery, National Advisory Committee for Aeronautics, [online] [accessed 21 May. 2018]. Available from Internet: https://digital.library.unt.edu/ark:/67531/metadc58436.

21. Pierpont, P. K.; Howell, R. R. 1951. Low-Speed Investigation of a Semi-Submerged Air Scoop With and Without Boundary Layer Suction, National Advisory Committee for Aeronautics (NACA), [online] [accessed 21 May. 2018]. Available from Internet https://ntrs.nasa.gov/search.jsp?R=19930093829.

H. Gökçe, U. C. Küçük, İ. Şahin

EFFECTS OF CURVATURE AND AREA DISTRIBUTION ON S-SHAPED SUBSONIC DIFFUSER PERFORMANCE

S u m m a r y

In this work, effects of curvature and area distribution on S-shaped subsonic diffuser performance are computationally investigated with commercially available flow solver Fluent. Free-stream Mach number was taken as 0.75 for all computational runs while sideslip and angle of attack values vary between 0 and 5. Intake performance criterions; DC (Distortion Coefficient) and PR (Pressure Recovery) are depicted from computational domain and dependence of these parameters to the varying centerline curvature and area ratio for each flight condition is discussed. Results of the current study indicate that low distortion and high PR values are obtainable with the high curvature at the diffuser entrance and smooth area increase through the duct. Furthermore, it was shown that conventional design approaches as investigated in the current study are strong enough for designing subsonic/transonic S-shaped intake if negative effects that may originate from intake/airframe integrations such as boundary layer ingestion can be neglected.

Keywords: S-Shaped subsonic diffuser, engine intake, CFD, fluent.

Received June 19, 2018 Accepted December 12, 2018 